\title{
Macrophage activation, age and sex effects of immunometabolism in obese asthma
}

\author{
Hashim A. Periyalit ${ }^{1,2}$, Lisa G. Wood ${ }^{1,2}$, Hayley A. Scott ${ }^{1,2}$, Megan E. Jensen ${ }^{1,2}$ \\ and Peter G. Gibson ${ }^{1,2,3}$
}

Affiliations: ${ }^{1}$ Centre for Asthma and Respiratory Diseases, Faculty of Health and Medicine, University of Newcastle, Callaghan, Australia. ${ }^{2}$ Hunter Medical Research Institute, New Lambton, Australia. ${ }^{3}$ Dept of Respiratory and Sleep Medicine, John Hunter Hospital, New Lambton, Australia.

Correspondence: Peter. G. Gibson, Priority Research Centre for Asthma and Respiratory Diseases, Level-2, Hunter Medical Research Institute, Lot-1, Kookaburra circuit, New Lambton, NSW 2305, Australia.

E-mail: peter.gibsonahnehealth.nsw.gov.au

ABSTRACT Obese asthma is characterised by infiltration of adipose tissue by activated macrophages and mast cells. The aim of this study was to examine the age and sex effects of immunometabolism in obese asthma.

Obese and non-obese asthmatic children and adults underwent spirometry, body composition assessment by dual energy X-ray absorptiometry and measurement of serum soluble CD163 (sCD163), tryptase, C-reactive protein (CRP) and other adipocytokines.

Plasma CRP $(p<0.01)$ and leptin $(p<0.01)$ were elevated in obese asthmatic adults, and sCD163 $(p=0.003)$ was elevated in obese asthmatic children. We observed significantly higher sCD163 in obese female children compared to obese female adults and male children, and higher CRP in obese female adults compared to obese male children and adults. Serum tryptase concentrations were not significantly different across age groups. sCD163 positively correlated with the proportion of android fat in obese female children $(\mathrm{r}=0.70, \mathrm{p}=0.003)$ and obese female adults $(\mathrm{r}=0.65, \mathrm{p}=0.003)$. In obese female children, $\mathrm{sCD} 163$ was inversely associated with forced expiratory volume in $1 \mathrm{~s} \%$ predicted $(\mathrm{r}=-0.55, \mathrm{p}=0.02)$ and was positively associated with the Asthma Control Questionnaire $(\mathrm{r}=0.57, \mathrm{p}=0.02)$.

Obese children with asthma have sex-specific macrophage activation, which may contribute to worse asthma control and lung function. The heterogeneous systemic inflammatory profile across age and sex suggests the existence of sub-phenotypes in obese asthma at the molecular level.

@ERSpublications

Macrophage activation is a determinant of pro-inflammatory effects of immunometabolism in childhood obese asthma http://ow.ly/ArCAH 


\section{Introduction}

Obesity is recognised as a risk factor for asthma across all age groups [1]. Additionally, obesity is related to poor asthma-specific quality of life and worse asthma control in adults and children. Increased systemic inflammation is now recognised as a hallmark of obesity and is related to negative metabolic effects [2]. Immune and inflammatory cells infiltrate adipose tissue and drive systemic inflammation and subsequent end-organ damage [3]. Key infiltrating cells are macrophages [4] and mast cells [5]. The presence of these immune cells in adipose tissue suggests its vital role as a key link between metabolic and immune functions (immunometabolism) in obesity. However, the role of macrophages and mast cells in obese asthma requires further investigation.

Age and sex may have significant effects on obese asthma. Ageing has been shown to have considerable effects on body composition [6] and metabolic dysfunction [7]. Furthermore, Lang et al. [8] found age to be an important effect modifier of asthma control and airway function in obese asthma. Various studies have reported that obese adults with asthma had high levels of C-reactive protein (CRP) $[9,10]$ and markers of macrophage infiltration [11]. Tryptase, a marker of mast cell activation, is also elevated in obese non-asthmatic adults [5]. However, there is conflicting evidence regarding the association of CRP $[12,13]$ with childhood obese asthma. To date, macrophage activation, measured using markers such as soluble CD163 (sCD163), has not been examined in childhood obese asthma. There is also strong evidence to suggest that, across age groups, the effect of obesity on asthma is more pronounced in females [14]. However, the mechanistic basis of this association is unknown. It is essential to have a greater understanding of the inflammatory and clinical profile of obese asthmatics across age and sex, in order to develop targeted treatment options. Therefore, the aim of this study was to determine whether there are age and sex effects on immunometabolism in obese asthma.

\section{Methods}

\section{Subjects}

Obese and non-obese children and adults with asthma were recruited from the general community and John Hunter Hospital (Newcastle, Australia) $[9,13]$. In this study, we assayed stored samples of plasma from these two previously described populations. Asthma was diagnosed on the basis of current (past 12 months) episodic respiratory symptoms, doctor-diagnosed asthma and in adults, airway hyperresponsiveness (AHR) to hypertonic saline, defined as a $>15 \%$ decline in forced expiratory volume in $1 \mathrm{~s}$ (FEV1) from baseline. Atopic status was determined by skin-prick allergy testing. Exclusion criteria included unstable asthma, systemic inflammatory diseases, respiratory diseases other than asthma and current smoking in adults. In children, obesity was defined as a body mass index (BMI) $\mathrm{z}$-score $\geqslant 1.64 \mathrm{SD}$ [15]. In adults, obesity was defined as a BMI $\geqslant 30 \mathrm{~kg} \cdot \mathrm{m}^{-2}$. All subjects gave written informed consent and the study was approved by the Hunter New England Human Research Ethics Committee (New Lambton, Australia; reference no: 12/11/21/5.05).

\section{Clinical assessment}

Clinical assessment was undertaken after an overnight fasting and after withholding antihistamines and asthma medications. Clinical asthma pattern and current asthma status were assessed using the Global Initiative for Asthma guidelines and the Asthma Control Questionnaire (ACQ) [16], respectively. Asthma stability was defined as no exacerbation, respiratory tract infection or oral corticosteroid use in the past 4 weeks. In children, BMI was calculated (weight $(\mathrm{kg}) /$ height $\left(\mathrm{m}^{2}\right)$ ) and converted to BMI $\mathrm{z}$-scores. All participants performed spirometry (Windows KoKo PFT System Version 4.9 2005; PDS Inc, Louisville, KY, USA). FEV1 and forced vital capacity are expressed as a percentage of the predicted value for age, sex and height.

\section{Sputum induction and analysis}

Participants underwent combined bronchial provocation testing and sputum induction with hypertonic saline (4.5\%) (ULTRA-NEB ultrasonic nebuliser, Model 2000; DeVilbiss Healthcare, Somerset, PA, USA), as described by Gibsonet al. [17]. AHR was defined as a $>15 \%$ decline in FEV 1 from baseline [17]. The dose-response slope (DRS) and log-transformed provocation dose causing a 15\% fall in FEV1 (PD15) were calculated. Sputum was selected, dispersed with dithiothreitol, and total cell counts and viability were determined. Cytospins were prepared, stained (May-Grunwald Giemsa; Sigma-Aldrich, Sydney, Australia) and a differential cell count obtained.

\section{Systemic inflammatory markers}

High-sensitivity CRP was measured in children from serum mixed with monoclonal antibody-coated polystyrene particles, specific for human CRP (Dimension Vista System CRP Flex Reagent Cartridge; Siemens Healthcare Diagnostics Inc., Newark, NJ, USA). In adults, ELISA (MP Biomedicals, Orangeburg, 
NY, USA) was used to measure CRP. Commercial ELISAs were used to measure plasma interleukin (IL)-6 (R\&D Systems, Minneapolis, MN, USA), serum leptin and adiponectin (Bio-Rad, Hercules, CA, USA) in children and adults. Assay sensitivity was $0.039 \mathrm{pg} \cdot \mathrm{mL}^{-1}, 3.1 \mathrm{pg} \cdot \mathrm{mL}^{-1}$ and $32.7 \mathrm{pg} \cdot \mathrm{mL}^{-1}$ for IL-6, serum leptin and serum adiponectin, respectively. All samples were tested in duplicate. Plasma tryptase was measured by Immuno CAP Tryptase assay (Phadia, Uppsala, Sweden), which measures total tryptase with a reportable range of 1-200 $\mu \mathrm{g} \cdot \mathrm{L}^{-1}$. Plasma levels of sCD163, a marker of macrophage activation [18], were measured using ELISA (Macro 163 kit; Trillium diagnostics, LLC, Bangor, ME, USA). The lower limit of detection was $0.23 \mathrm{ng} \cdot \mathrm{mL}^{-1}$.

\section{Body composition assessment}

A total body scan was performed using dual-energy X-ray absorptiometry (Lunar Prodigy Series; GE Medical Systems, Madison, WI, USA). Percentage of android fat distribution was calculated as: android fat $(\mathrm{g}) /$ total fat $(\mathrm{g}) \times 100$.

\section{Statistical analysis}

Data were summarised by descriptive statistics using mean \pm sD for parametric data and median (interquartile range) for non-parametric data. Group comparisons for continuous data were performed using either ANOVA with Holm-Sidak's post hoc test (parametric data) or the Kruskal-Wallis test with Dunn's post hoc test (non-parametric data). For correlation analysis, two-tailed Pearson's (parametric data) or Spearman's (non-parametric) correlation coefficient was used (Graph Pad Prism software version 6.0e; GraphPad Software, La Jolla, CA, USA). A p-value $\leqslant 0.05$ was regarded as statistically significant.

\section{Results}

Clinical characteristics across age groups when categorised according to BMI

Table 1 describes the subject characteristics of asthmatic children $(n=49)$ and adults $(n=158)$ included in the study. Obese and non-obese adults had significantly greater airflow limitation (FEV1 \% predicted), compared to obese children with asthma $(\mathrm{p}=0.005)$. In obese children, the daily dose of inhaled corticosteroids (ICS) was significantly higher than in non-obese children $\left(348 \pm 35\right.$ versus $105 \pm 28 \mu \mathrm{g} \cdot \mathrm{day}^{-1}$, $\mathrm{p}<0.01)$. Similarly, adults required significantly higher doses of ICS compared to their non-obese counterparts $\left(1399 \pm 92\right.$ versus $\left.956 \pm 88 \mu \mathrm{g} \cdot \mathrm{day}^{-1}, \mathrm{p}=0.002\right)$. Baseline atopic status did not differ among groups. AHR, measured by PD15, was significantly lower in obese adults when compared to non-obese children $(\mathrm{p}=0.004)$.

TABLE 1 Clinical characteristics of the asthmatic children and adults included in the study

\begin{tabular}{|c|c|c|c|c|c|}
\hline & \multicolumn{2}{|c|}{ Children } & \multicolumn{2}{|c|}{ Adults } & \multirow[t]{2}{*}{ p-value } \\
\hline & Obese & Non-obese & Obese & Non-obese & \\
\hline Subjects $\mathrm{n}$ & 34 & 15 & 85 & 73 & \\
\hline Age years & $12 \pm 2$ & $14 \pm 2$ & $49 \pm 15$ & $51 \pm 16$ & \\
\hline Females $\%$ & 38 & 60 & 60 & 59 & 0.99 \\
\hline BMI & $2.1 \pm 0.3^{+}$ & $0.3 \pm 1.4^{+}$ & $35.4 \pm 4.1$ & $26.6 \pm 3.2$ & \\
\hline Atopy & 25 (73) & $13(86)$ & $63(75)$ & $54(75)$ & 0.78 \\
\hline FEV $1 \%$ predicted & $92.8 \pm 10.7$ & $87.2 \pm 11.6$ & $81.9 \pm 19.1 *$ & $79.8 \pm 20.3^{*}$ & 0.005 \\
\hline FVC \% predicted & $100.8 \pm 9.4$ & $96.1 \pm 12$ & $93.2 \pm 14.7$ & $96.1 \pm 18$ & 0.10 \\
\hline $\mathrm{FEV}_{1} / \mathrm{FVC}$ & $79.2 \pm 6$ & $79.2 \pm 8.01$ & $70.9 \pm 9.7^{\#}$ & $66.8 \pm 10.8^{*, \#, 9}$ & $<0.01$ \\
\hline ACQ Score & $0.7(0.4-1.2)$ & $0.7(0.4-1.3)$ & $1(0.4-1.6)$ & $0.7(0.4-1.4)$ & 0.18 \\
\hline \multicolumn{6}{|l|}{ GINA pattern } \\
\hline Intermittent & $12(35)$ & $5(36)$ & 27 (32) & $22(30)$ & \\
\hline Mild persistent & $6(18)$ & $7(50)$ & $13(15)$ & $10(14)$ & \\
\hline Moderate persistent & $11(32)$ & $2(14)$ & 31 (37) & $29(40)$ & \\
\hline Severe persistent & $5(15)$ & 0 & $14(16)$ & $12(16)$ & \\
\hline PD15 mL & $3.9(1.4-12.5)$ & $1.6(0.4-3.7)$ & $6.7(3.9-11.7)^{\#}$ & $5.56(0.7-8.6)$ & 0.004 \\
\hline
\end{tabular}

Data are presented as mean \pm SD, $n(\%)$ or median (interquartile range), unless otherwise stated. Bold indicates statistical significance. BMI: body mass index; FEV1: forced expiratory volume in $1 \mathrm{~s}$; FVC: forced vital capacity; ACQ: Asthma Control Questionnaire; GINA: Global Initiative for Asthma; PD15: provocation dose causing a $15 \%$ fall in FEV1. ${ }^{*}: p<0.05$ versus obese children; ${ }^{\#}: p<0.05$ versus non-obese children; १: $p<0.05$ versus obese adults; ${ }^{+}$: BMI z-scores. 
TABLE 2 Systemic and airway inflammatory markers in asthmatic children and adults when categorised according to body mass index

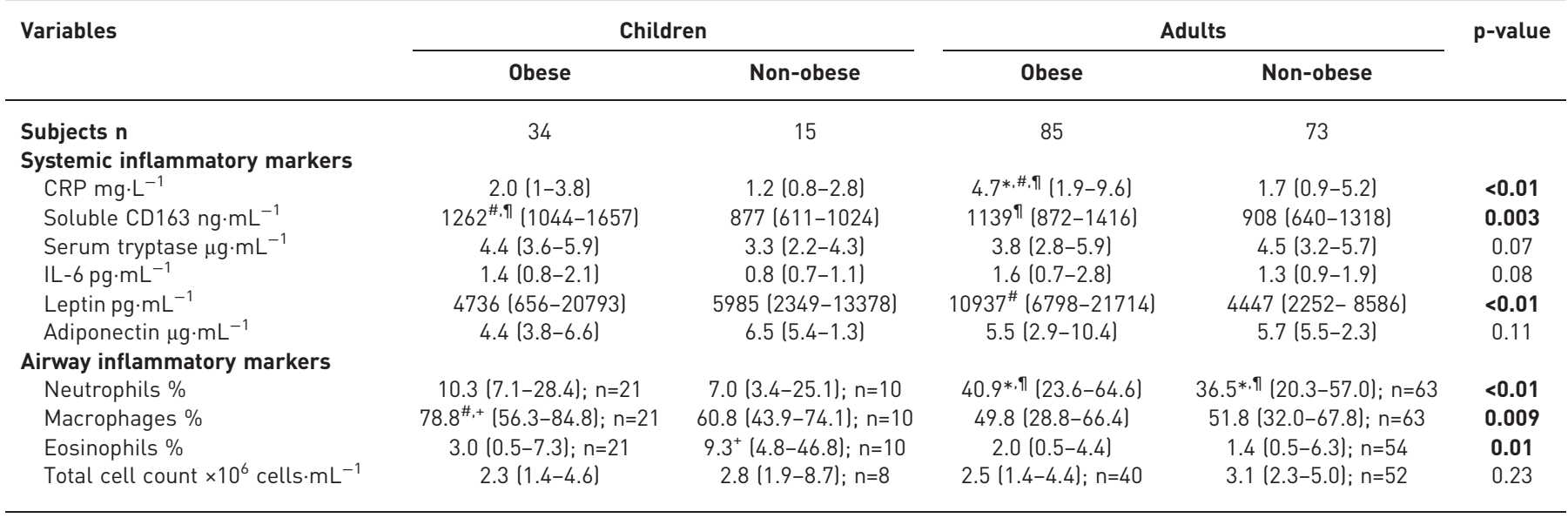

Data are presented as median (interquartile range), unless otherwise stated. Bold indicates statistical significance. CRP: C-reactive protein; IL: interleukin. *: $p<0.05$ versus obese children; ${ }^{\#}: p<0.05$ versus non-obese adults; ${ }^{\natural}: p<0.05$ versus non-obese children; ${ }^{+}: p<0.05$ versus obese adults.

Inflammatory markers across age groups when categorised according to BMI

Systemic and airway inflammatory markers are described in table 2. Obese adults with asthma had significantly higher CRP concentrations than non-obese adults and obese and non-obese children $(\mathrm{p}<0.01)$. In contrast, $\mathrm{sCD} 163$ was significantly higher in obese children $(\mathrm{p}=0.003)$, when compared to non-obese children and non-obese adults. We observed a positive trend for higher plasma tryptase, a biomarker of mast cell activation, among obese children when compared to non-obese children $(p=0.014)$; however, it was not significantly different across age groups $(\mathrm{p}=0.07)$. The adipokine leptin was elevated in obese adults with asthma $(\mathrm{p}<0.01)$.

Obese asthmatic children had a significantly higher percentage of macrophages in their airways compared to other groups. The percentage of neutrophils was elevated in adults, compared to children with asthma (table 2).

Systemic inflammatory profile in obese asthmatics according to age and sex

Obese female adults with asthma had significantly higher CRP $(\mathrm{p}<0.01)$ when compared to obese male adults and children with asthma (fig. 1a). In terms of macrophage activation, sCD163 was significantly higher in obese female children with asthma, when compared to obese female adults $(p=0.01)$ and obese male children ( $\mathrm{p}=0.03)$ with asthma (fig. $1 b$ ).
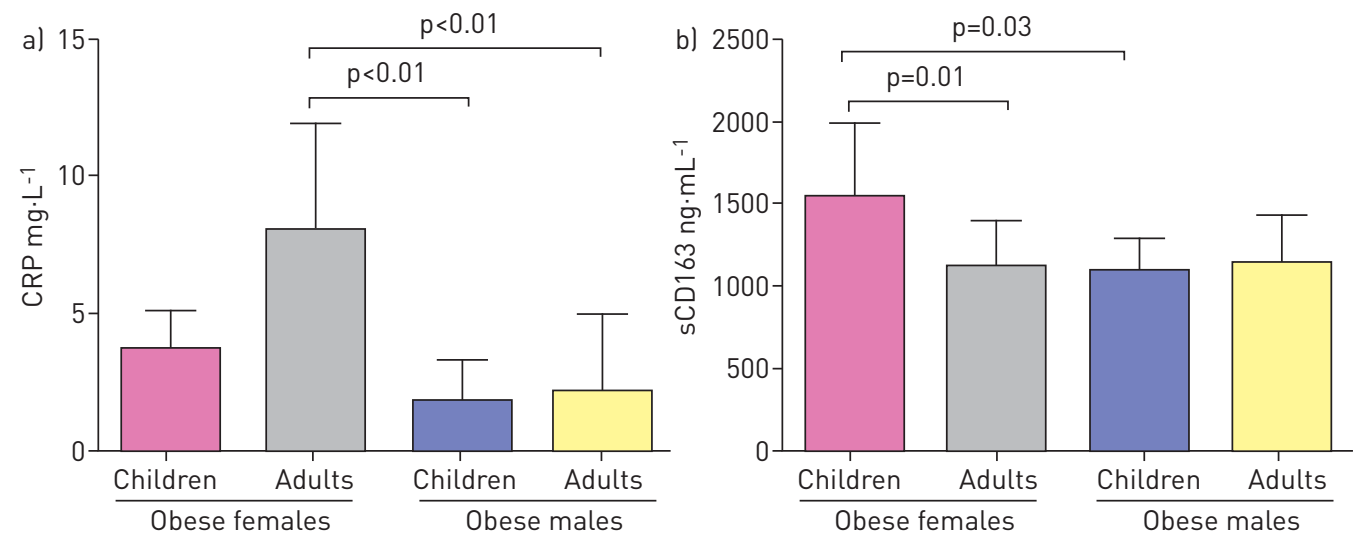

FIGURE 1 Systemic inflammation in obese asthmatics across age and sex. a) C-reactive protein (CRP) and b) soluble CD163 (sCD163). 
sCD163 correlated positively with percentage of android fat in obese asthmatic female children $(\mathrm{r}=0.70$, $\mathrm{p}=0.003$ ) (fig. $2 \mathrm{a})$ and adults $(\mathrm{r}=0.65, \mathrm{p}=0.003)$. No significant correlation was observed between $\mathrm{sCD} 163$ and percentage of android fat in obese male children with asthma ( $r=0.02, p=0.94)$ (fig. 2b). CRP correlated positively with percentage of android fat $(r=0.67, p=0.002)$ and negatively with percentage of gynoid fat $(\mathrm{r}=-0.55, \mathrm{p}=0.014)$ in obese female children with asthma. However, no significant correlations were found between CRP and body composition in female adults. In obese female children with asthma, we observed a positive correlation between $\mathrm{sCD} 163$ and ACQ $(\mathrm{r}=0.57, \mathrm{p}=0.02)$ (fig. 3a) and a negative correlation with measure of airflow limitation ( $F E V 1)(r=-0.55, p=0.02)$ (fig. 3b). No significant correlations were observed between tryptase levels and body composition.

\section{Discussion}

This is the first study to our knowledge, to report a heterogeneous systemic inflammatory profile across age and sex in obese asthma and to identify macrophage activation as a determinant of this observation. The predominant macrophage activation demonstrated by obese female asthmatic children, when compared to their adult counterparts, suggests age- and sex-specific effects of immunometabolism in obese asthma. Moreover, this novel finding suggests distinct orchestration of immune cell activation and morphogenesis of adipose tissue at a molecular level across age and sex in obese asthma. From a clinical perspective, understanding this phenomenon is critical to enable us to develop age- and sex-specific therapeutic strategies.

Macrophage activation, assessed by measuring sCD163, has been reported to be significantly associated with increased BMI $[19,20]$ and related comorbidities, such as type-2 diabetes [21] and hypertension [20] in obese adults. SCD163 is the soluble form of CD163 (glycosylated membrane protein expressed exclusively by cells of monocytic lineage), which is cleaved following lipopolysaccharide- or free fatty acid-mediated activation of adipose tissue resident macrophages and released into systemic circulation [18]. The systemic level of sCD163 has now been recognised as a measure of macrophage activation in various obesity-related pro-inflammatory conditions. However, to date, there is little evidence to suggest an association of macrophage activation with obese asthma. Sideleva et al. [11] examined adipose tissue inflammation in obese asthma and observed an increased macrophage infiltration of visceral adipose tissue, when controlled for BMI. Our data also suggest that macrophage activation may have a pivotal role in determining increased obesity-related metabolic activity of adipose tissue and translation of these effects to clinical aspects of obese asthma, particularly in obese female children.

We also examined serum tryptase as a marker of mast cell activation in obese asthma [5]. The presence of mast cells noted in adipose tissue in obese mice [5], prior to macrophage recruitment, is suggestive of a pivotal role for mast cells in regulating immunometabolism in obesity. In view of our observation of macrophage activation in obese asthmatic children, we expected a similar trend with mast cell activation. However, tryptase was significantly increased only in obese children, compared to non-obese children and not across all age groups. This may be explained by the effect of age on tryptase, as tryptase levels increase in adults independent of BMI [22], which may have confounded our analysis. In another human study, WARD et al. [23] also found no association between BMI and tryptase in obese and non-obese children with and without glucose intolerance and diabetes mellitus $(\mathrm{p}=0.068)$. Hence, further assessment of tryptase levels in obese asthmatics is needed. The distinct levels of sCD163, in the absence of a similar
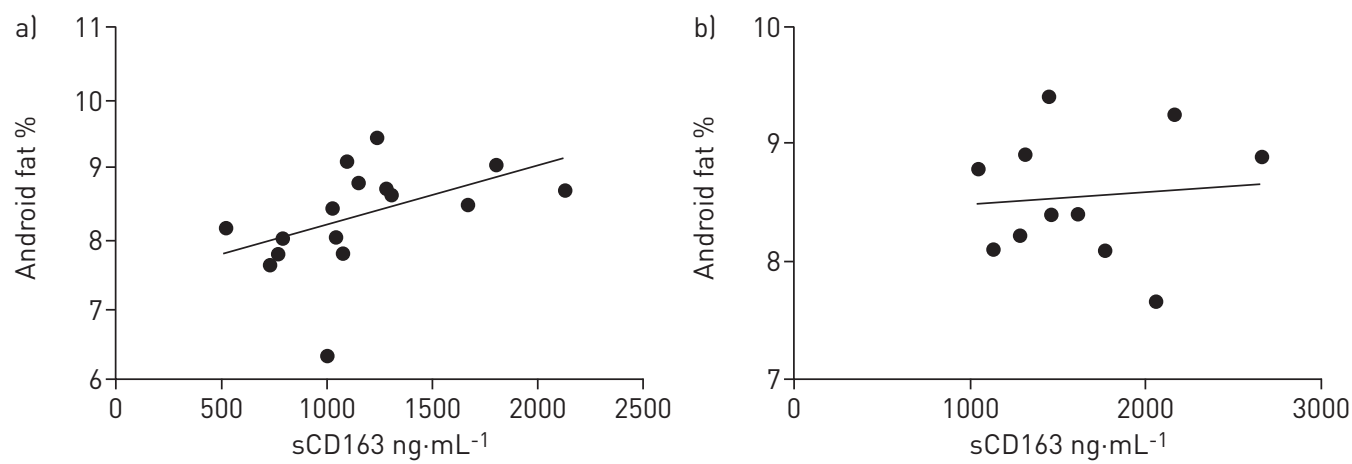

FIGURE 2 Sex-specific effects of central obesity on macrophage activation. Android fat versus soluble CD163 (sCD163) in a) obese female children $(\mathrm{r}=0.70, \mathrm{p}=0.003)$ and $\mathrm{b})$ obese male children $(\mathrm{r}=0.02, \mathrm{p}=0.94)$. 

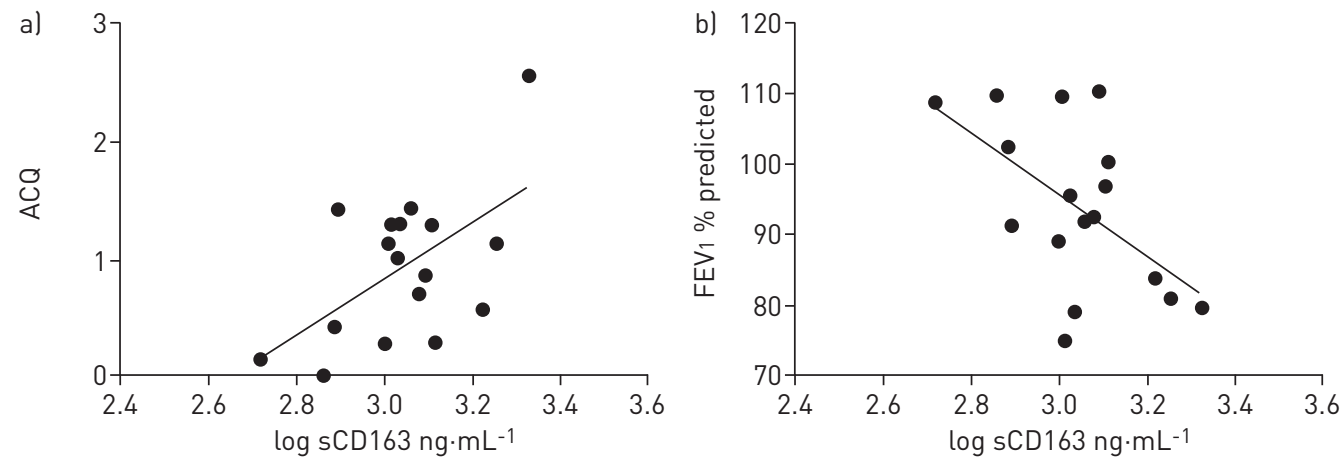

FIGURE 3 Association between macrophage activation and clinical aspects in obese female children with asthma. a) Asthma Control Questionnaire (ACQ) and b) forced expiratory volume in $1 \mathrm{~s}$ (FEV1) versus log soluble CD163 (sCD163) ( $\mathrm{r}=0.57, \mathrm{p}=0.02$ and $\mathrm{r}=-0.55, \mathrm{p}=0.02$, respectively).

pattern with tryptase, suggest a macrophage-specific immune cell activation pathway in obese asthma across age groups.

In this study, obese female children had significantly higher sCD163 when compared across age and sex. We propose that, in addition to the effects of body composition, a multitude of age- and sex-specific biological mechanisms might contribute to the metabolic activity of adipose tissue. Adipose tissue distribution is heavily influenced by sex, with sex-related patterns becoming apparent during puberty. However, in obese female children, a BMI-related increase in androgens [24, 25] may favour central adiposity. In addition, obese female children have a greater degree of obesity-induced insulin resistance [26], and the compensatory hyperinsulinaemia may further facilitate accumulation of visceral fat [27]. Furthermore, free fatty acid flux, which is an important determinant of metabolic activation of adipose tissue, has been reported to be higher in obese female children when compared to their male counterparts [28]. These complex biological interactions might lead to the development of a unique metabolome favouring macrophage activation in obese female children with asthma.

While there is clear evidence of increased systemic inflammation in obese asthmatic adults $[9,29]$, there is conflicting evidence regarding systemic inflammation in obese childhood asthma. CooK et al. [30] first reported elevated CRP in obese children, defined using the Ponderal index (weight $/$ height $^{3}$ ). However, it is uncertain to what extent the Ponderal index would have reflected the degree of adiposity. Similarly, KHAN et al. [31], in a cross-sectional study, found significantly elevated high-sensitivity CRP in obese children with asthma, compared to non-obese asthmatic and non-asthmatic children. By further analysis, they observed an independent association between asthma and obesity with high-sensitivity CRP in obese children with asthma. However, in another study [32], IL-6, which is the main inducer of hepatic production of CRP, was not found to be significantly raised in obese children. Moreover, analysis of National Health and Nutrition Examination Survey III data identified elevated CRP levels $\left(>0.22 \mathrm{mg} \cdot \mathrm{L}^{-1}\right)$ in only one in five overweight children [33]. We found that CRP was not elevated in obese children with asthma. In contrast, sCD163 was elevated in obese compared to non-obese children with asthma. Together, these data show age-specific effects of immunometabolism in obese asthma.

Recently, body composition measures have gained greater attention in studies examining obesity-related comorbidities. Most of the association studies reveal that abdominal obesity (waist circumference $>88 \mathrm{~cm}$ in females and $>102 \mathrm{~cm}$ in males) has more impact on risk of developing asthma than general obesity. In their large prospective study examining the association of abdominal obesity and incident asthma in adults, BRUMPTON et al. [34] observed that abdominal obesity was a significant risk factor for asthma (OR 1.46, 95\% CI 1.52-2.52), particularly in females, even after adjusting for general obesity. We found that body composition was a determinant of inflammatory marker levels. This is the first study to link sCD163 and percentage of android fat (fat distribution around the abdomen). There was a significant correlation between sCD163 and percentage of android fat in obese female children and adults, highlighting increased depot-specific metabolic activity of adipose tissue in obesity. Interestingly, the significantly high systemic levels of CRP observed in obese female adults, when compared across sex, did not correlate with percentage of android fat.

Even though CRP is primarily secreted by the liver, when induced by IL-6, IL-1 $\beta$ and tumour necrosis factor- $\alpha$, there are other factors that could affect systemic levels of CRP, particularly vascular reactivity [35]. Thus, our data suggest that, CRP, which is an excellent marker of systemic inflammation, may not be a specific reflection of metabolic activity in adipose tissue of obese female adults with asthma. 
A large number of cross-sectional and longitudinal studies have reported worse asthma control and increased asthma severity in obese individuals. The significantly higher percentage of macrophages that we observed in the induced sputum of obese children, along with their altered phenotype [36] and activity [37], highlight the potential implication of airway macrophages on clinical aspects of obese asthma. Furthermore, the enhanced reactivity of alveolar macrophages from overweight/obese adult asthmatics to lipopolysaccharide, particularly when they were primed ex vivo with high dose of leptin, was demonstrated in an elegant study by LugOGo et al. [36]. The authors also observed leptin-induced production of pro-inflammatory cytokines from alveolar macrophages of overweight/obese asthmatics. Together, these findings highlight the potential role of airway macrophages in translating the effects of increased systemic inflammation to the airways. In addition, they also provide a greater understanding of a mechanistic link for previously observed leptin-mediated effects on airway characteristics of obese asthmatics [38]. Recently, KIM et al. [39] found mice fed on a high fat diet and ob/ob (genetically modified leptin deficient) mice fed on a regular diet developed significantly worse AHR. They have attributed this phenomenon to an inflammasome-mediated pathway triggered by macrophage activation in adipose tissue and involving IL-17. They further observed an increased expression of IL-1 $\beta$ and inflammasome component of NLRP3 in the lung tissue of obese mice, suggestive of an effect of macrophage activation on inflammometry lung tissue in obesity. Similarly, our novel finding of a correlation between sCD163, ACQ and FEV $1 \%$ predicted in obese female children suggests that, indeed, there is an effect of macrophage activation on clinical aspects of obese childhood asthma. Furthermore, increased macrophage activation in obese children with asthma may contribute to their steroid non-responsiveness [40], which ultimately may lead to unwanted side-effects from significantly high doses of steroid therapy.

This study, being designed as cross-sectional and retrospective, cannot fully address all possible interactions between macrophage and mast cell activation and negative metabolic effects in obese asthma. A limitation of this study is the lack of a non-asthmatic control group to determine if these relationships are related to the presence of disease. However, the associations between these biomarkers and asthma control and lung function suggest their direct relevance to asthma. More longitudinal and interventional studies are warranted to address this issue.

\section{Conclusion}

In conclusion, we have shown for the first time that there are age- and sex-specific effects on macrophage activation in obese asthma. Our data highlights sCD163 as a potential biomarker of asthma control and disease severity in obese childhood asthma. Macrophage activation in obese childhood asthma may contribute to the steroid non-responsiveness in this population. The association of sCD163 with android fat is in line with the already known increased metabolic activity of visceral adipose tissue. Evidence from this study suggests the need to characterise sub-phenotypes of obese asthma at a molecular level, which may enable us to have a greater understanding of the distinct immunological mechanisms and to identify specific therapeutic targets across age and sex.

\section{Acknowledgements}

We would like to thank Heather Powell (Centre for Asthma and Respiratory Diseases, Faculty of Health and Medicine, University of Newcastle, Callaghan, Australia and Dept of Respiratory and Sleep Medicine, John Hunter Hospital, New Lambton, Australia) for her help with statistical analysis and Kellie Fakes (Centre for Asthma and Respiratory Diseases, Faculty of Health and Medicine, University of Newcastle, Callaghan) for sCD163 estimation.

\section{References}

Ford ES. The epidemiology of obesity and asthma. J Allergy Clin Immunol 2005; 115: 897-909.

Hotamisligil GS. Inflammation and metabolic disorders. Nature 2006; 444: 860-867.

Mathis D. Immunological goings-on in visceral adipose tissue. Cell metabolism 2013; 17: 851-859.

Weisberg SP, McCann D, Desai M, et al. Obesity is associated with macrophage accumulation in adipose tissue. J Clin Invest 2003; 112: 1796-1808.

5 Liu J, Divoux A, Sun J, et al. Genetic deficiency and pharmacological stabilization of mast cells reduce diet-induced obesity and diabetes in mice. Nat Med 2009; 15: 940-945.

6 Buffa R, Floris GU, Putzu PF, et al. Body composition variations in ageing. Coll Antropol 2011; 35: 259-265.

7 Tchkonia T, Morbeck DE, Von Zglinicki T, et al. Fat tissue, aging, and cellular senescence. Aging Cell 2010; 9 : 667-684.

8 Lang JE, Hossain J, Dixon AE, et al. Does age impact the obese asthma phenotype? Longitudinal asthma control, airway function, and airflow perception among mild persistent asthmatics. Chest 2011; 140: 1524-1533.

9 Scott HA, Gibson PG, Garg ML, et al. Airway inflammation is augmented by obesity and fatty acids in asthma. Eur Respir J 2011; 38: 594-602.

10 Butland BK, Strachan DP, Rudnicka AR. C-reactive protein, obesity, atopy and asthma symptoms in middle-aged adults. Eur Respir J 2008; 32: 77-84.

11 Sideleva O, Suratt BT, Black KE, et al. Obesity and asthma: an inflammatory disease of adipose tissue not the airway. Am J Respir Crit Care Med 2012; 186: 598-605. 
12 Michelson PH, Williams LW, Benjamin DK, et al. Obesity, inflammation, and asthma severity in childhood: data from the National Health and Nutrition Examination Survey 2001-2004. Ann Allergy Asthma Immunol 2009; 103: $381-385$.

13 Jensen ME, Gibson PG, Collins CE, et al. Airway and systemic inflammation in obese children with asthma. Eur Respir J 2013; 42: 1012-1019.

14 Sood A. Sex differences: implications for the obesity-asthma association. Exerc Sport Sci Rev 2011; 39: 48-56.

15 Kuczmarski RJ, Ogden CL, Grummer-Strawn LM, et al. CDC growth charts: United States. Adv Data 2000; 8: $1-27$.

16 Juniper EF, O'Byrne PM, Guyatt GH, et al. Development and validation of a questionnaire to measure asthma control.Eur Respir J 1999; 14: 902-907.

17 Gibson PG, Wlodarczyk JW, Hensley MJ, et al. Epidemiological association of airway inflammation with asthma symptoms and airway hyperresponsiveness in childhood. Am J Respir Crit Care Med 1998; 158: 36-41.

18 Møller HJ. Soluble CD163. Scand J Clin Lab Invest 2012; 72: 1-13.

19 Fjeldborg K, Christiansen T, Bennetzen M, et al. The macrophage specific serum marker, soluble CD163, is increased in obesity and reduced after dietary induced weight loss. Obesity (Silver Spring) 2013; 21: 2437-2443.

20 Al-Daghri NM, Al-Attas OS, Bindahman LS, et al. Soluble CD163 is associated with body mass index and blood pressure in hypertensive obese Saudi patients. Eur J Clin Invest 2012; 42: 1221-1226.

21 Zanni MV, Burdo TH, Makimura $\mathrm{H}$, et al. Relationship between monocyte/macrophage activation marker soluble CD163 and insulin resistance in obese and normal-weight subjects. Clin Endocrinol 2012; 77: 385-390.

22 Fenger RV, Linneberg A, Vidal C, et al. Determinants of serum tryptase in a general population: the relationship of serum tryptase to obesity and asthma. Int Arch Allergy Immunol 2012; 157: 151-158.

23 Ward BR, Arslanian SA, Andreatta E, et al. Obesity is not linked to increased whole-body mast cell burden in children. J Allergy Clin Immunol 2012; 129: 1164-1166.

24 Reinehr T, de Sousa G, Roth CL, et al. Androgens before and after weight loss in obese children. J Clin Endocrinol Metab 2005; 90: 5588-5595.

25 Reinehr T, Kulle A, Wolters B, et al. Steroid hormone profiles in prepubertal obese children before and after weight loss. J Clin Endocrinol Metab 2013; 98: E1022-E1030.

26 Travers SH, Jeffers BW, Bloch CA, et al. Gender and Tanner stage differences in body composition and insulin sensitivity in early pubertal children. J Clin Endocrinol Metab 1995; 80: 172-178.

27 Caprio S, Hyman LD, McCarthy S, et al. Fat distribution and cardiovascular risk factors in obese adolescent girls: importance of the intraabdominal fat depot. Am J Clin Nutr 1996; 64: 12-17.

28 Adler-Wailes DC, Periwal V, Ali AH, et al. Sex-associated differences in free fatty acid flux of obese adolescents. J Clin Endocrinol Metab 2013; 98: 1676-1684.

29 Sood A, Ford ES, Camargo CA, Jr. Association between leptin and asthma in adults. Thorax 2006; 61: 300-305.

30 Cook DG, Mendall MA, Whincup PH, et al. C-reactive protein concentration in children: relationship to adiposity and other cardiovascular risk factors. Atherosclerosis 2000; 149: 139-150.

31 Khan UI, Rastogi D, Isasi CR, et al. Independent and synergistic associations of asthma and obesity with systemic inflammation in adolescents. J Asthma 2012; 49: 1044-1050.

32 Wärnberg J, Moreno LA, Mesana MI, et al. Inflammatory mediators in overweight and obese Spanish adolescents. The AVENA Study. Int J Obes Relat Metab Dis 2004; 28 Suppl. 3, S59-S63.

33 Visser M, Bouter LM, McQuillan GM, et al. Low-grade systemic inflammation in overweight children. Paediatr 2001; 107: E13.

34 Brumpton B, Langhammer A, Romundstad P, et al. General and abdominal obesity and incident asthma in adults: the HUNT study. Eur Respir J 2013; 41: 323-329.

35 Inoue N. Vascular C-reactive protein in the pathogenesis of coronary artery disease: role of vascular inflammation and oxidative stress. Cardiovasc Hematol Disord Drug Targets 2006; 6: 227-231.

36 Lugogo NL, Hollingsworth JW, Howell DL, et al. Alveolar macrophages from overweight/obese subjects with asthma demonstrate a proinflammatory phenotype. Am J Respir Crit Care Med 2012; 186: 404-411.

37 Fernandez-Boyanapalli R, Goleva E, Kolakowski C, et al. Obesity impairs apoptotic cell clearance in asthma. J Allergy Clin Immunol 2013; 131: 1041-1047.

38 Shore SA, Schwartzman IN, Mellema MS, et al. Effect of leptin on allergic airway responses in mice. J Allergy Clin Immunol 2005; 115: 103-109.

39 Kim HY, Lee HJ, Chang YJ, et al. Interleukin-17-producing innate lymphoid cells and the NLRP3 inflammasome facilitate obesity-associated airway hyperreactivity. Nat Med 2014; 20: 54-61.

40 Forno E, Lescher R, Strunk R, et al. Decreased response to inhaled steroids in overweight and obese asthmatic children. J Allergy Clin Immunol 2011; 127: 741-749. 